\title{
Analysis of design and technological solutions of strip sowing machines
}

\author{
Dmitry Melnikov ${ }^{1}$, Ivan Ignatenko ${ }^{1}$, Yuri Tsarev $^{1, *}$, and Dmitry Vivchar $^{1}$ \\ ${ }^{1}$ Don State Technical University, 1, pl. Gagarina, 344003, Rostov-on-Don, Russia
}

\begin{abstract}
General analysis of the design and technological solutions of machines for strip sowing is given. The task is to find a middle ground between constructive and technological solutions and zonal conditions that would ensure high productivity of the cultivated crop at minimal cost. The analysis shows that a promising direction is the use of combined aggregates designed for surface tillage, both for sowing grain crops and for row crops, with simultaneous application of mineral fertilizers and harrowing.
\end{abstract}

\section{Introduction}

General analysis of the design and technological solutions of strip sowing machines shows that all of it have a number of disadvantages [1]. In addition, it is used only when sowing according to a certain technology, mainly on well-prepared soil and for certain zonal conditions.

In the Russian Federation, currently in the family of grain seeders, the basic machine is a seed-fertilizer seeder $S 3-3,6 A$ [2]. Base seeder $S 3-3,6$ (figure 1) oequipped with universal grain and fertilizer sowing machines, hydraulic lifting mechanism, centralized drive, pneumatic wheels, signaling. Seeders are unified in the kind by seed box compartment, lifting mechanisms, seed tubes, frame constructions.

Other seeders of domestic production are arranged in similar pattern.: $S Z P-3,6$; $S Z U-12$; SZT-3, 6 etc. [3]

"Corresponding author: ycarev@donstu.ru 


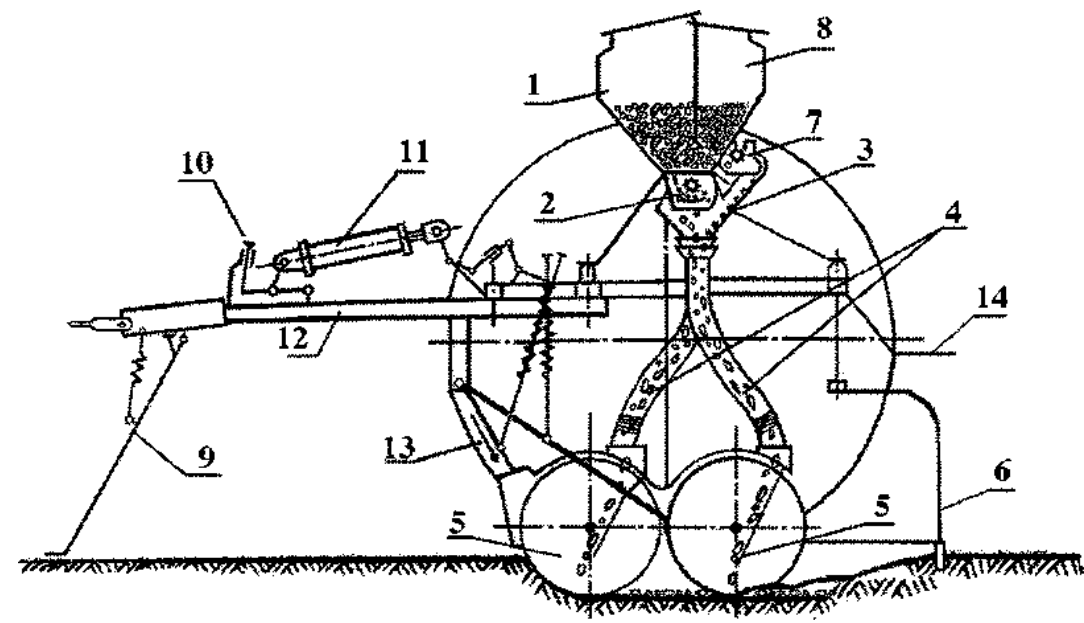

1 - seed box compartment; 2 - seed sowing apparatus; 3 - tray; 4 - seed tubes; 5 - doubledisk boat; 6 - covering body; 7 - fertilizer dispenser; 8 - fertilizer tray section; 9 - support; 10 depth adjuster; 11 - hydraulic cylinder; 12 - frame; 13 - pneumatic wheel; 14 - footboard

Fig. 1. Sheme of seed-fertilizer seeder S3-3,6A.

Most grain seeders in Russia are produced with a double-disc sowing machine, which works better in fields with a heterogeneous agricultural background. However, such a coulter cannot lead a strip sowing.

The mechanical seeders of foreign manufacturers are very famous: $D 9-40(60,120)$ by Amazonen Werke company (Germany), INTEGRA by KUHN company (France), HD by Great Plains (USA) company, which, unlike Russian ones, use keeled openers that give the best result in well-aligned fields.

The main innovations in grain seeders go along the path of sowing devices modernization. Pneumatic seeders with a central metering device and a pneumatic distributor (centralized metering system, CMS) are common abroad: Citan, DMC Primera 602 by Amazonen Werke (Germany), «Akkord» (Germany), Solitair 9 - LEMKEN (Germany), VENTA, FASTLINER, TF - KUHN (France), C-6ПM.1, CПУ-6 (Russia). In a number of seeders — «Stockland» (Sweden), «Jones» (England) — instead of pneumatic, CMS with centrifugal sowing devices is used.

As an example, in fig. 2, there showen the «Akkord» (Germany) seeder with pneumatic distributor, and in fig. 2, b there is a scheme of a seeder with centrifugal distributor «Stockland» (Sweden). 
a. «Akkord» seeder sheme

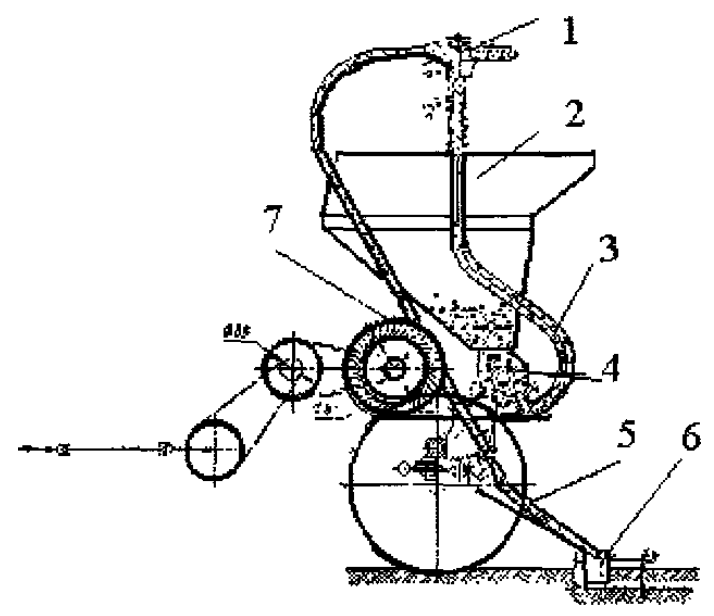

1 - seed head; 2 - hopper; 3 - central seed tube; 4 - metering roller; 5 - seed tube; 6 - opener; 7 - blower

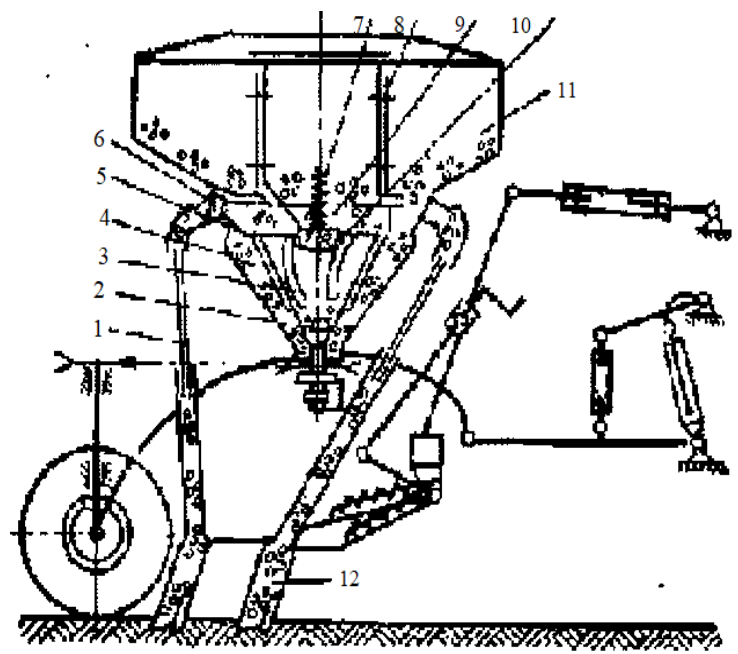

b. «Stockland» seeder sheme

1 - seed tube; 2 - fence window; 3 - impeller; 4 - feed chamber; 5 - distributor; 6 - pipe; 7 spring; 8 - grass hopper; 9 - cap; 10 - metering cap; 11 - grain hopper; 12 - opener.

Fig. 2. Openers on foreign integral grain seeders.

The analysis shows that, despite the obvious progress in sowing devices improving, there is no progress in the openers designs of grain seeders, openers remain invariably anchor or keeled, requiring a leveled old plowed field. Anchor ones have less traction resistance, but do not condense the furrow bottom, keeled ones condense the furrow bottom, are more stable, but have increased traction resistance. Openers make a narrow groove, suitable only for gutter row sowing. In principle, such seeders cannot carry out strip sowing.

The use in some cases of additional devices for seedless continuous sowing without pronounced rows or ribbons does not change the overall picture.

The resource-saving task that has come to the fore required the creation of more productive sowing equipment that combines several operations. The widespread introduction of minimal tillage has led to the combined machines existing — sowing 
complexes combining tillage, sowing and top dressing. It allows sowing in moist, just loosened soil, eliminating the harmful gap between tillage and sowing.

Analysis shows that the combination machines design is currently achieved by three layout methods [4]:

1. the combination of several autonomous (running gear) machines in a composite unit;

2. the combination of several working bodies on a single machine frame;

3 . the use on the machine of universal working bodies that perform several operations at once.

The most economical and small third way, but the development of universal working bodies - difficult scientific task. Practice uses for combination the most obvious first way.

The most complete combination of operations provides a combination of primary, presowing processing and sowing: the plow is connected to the seeder. Figure 3 shows a Kverneland combination unit consisting of a reversible plow and a pneumatic type seeder «Akkord».

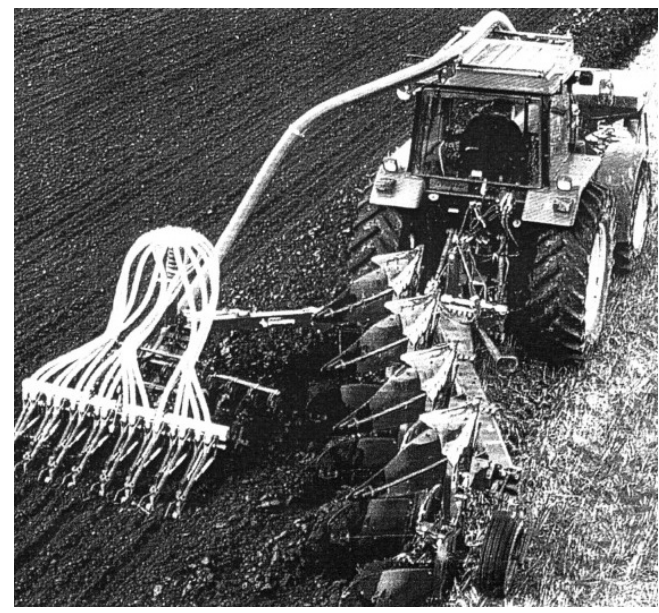

Fig. 3. Kverneland Combined Unit with reversible plow and air seeder.

Unit layout feature: the seeder is located on the side of the reversible plow. The use of pneumatic transport allowed to place heavy seed hopper on the front hitch. Keeled seeders go through a freshly plowed field without high-quality pre-sowing. Crushing of blocks obtained by plowing, leveling the surface of the field is not provided, therefore, the stability of the coulters and the uniform depth of sowing are unsatisfactory.

The combination of basic, pre-sowing treatment and sowing has not yet been technically worked out due to the folding of energy-intensive plowing. The rejection of the main processing simplified the task of creating a combined sowing technique. Separate-aggregate (modular) seeders, called sowing complexes [5], performing pre-sowing processing and sowing with fertilizers, avoiding plowing, became widespread.

Such sowing complexes are produced by many foreign companies such as John Deere (USA), Flexi Coil (Canada), Horsch - Agro-Union (Germany - Ukraine) etc. Domestic sowing complexes and aggregates: PPA-5,4 (Chelyabinsk), PPA-7,2 "Yaroslavich" (Yaroslavl RTP), PPABM-14,7, PK-8,5 "Kuzbass" (Kemerovo) etc. These units include, as a rule, seeder-cultivator with paw openers, hopper with metering devices on special trolley, pneumatic conveying system with flow distributors, connected by seed tubes with openers and press-on working bodies. Figure 4 shows a tillage and sowing complex «Concord» by Case JH (USA) company. It is a combination of tractor, heavy cultivator and air seeder. 


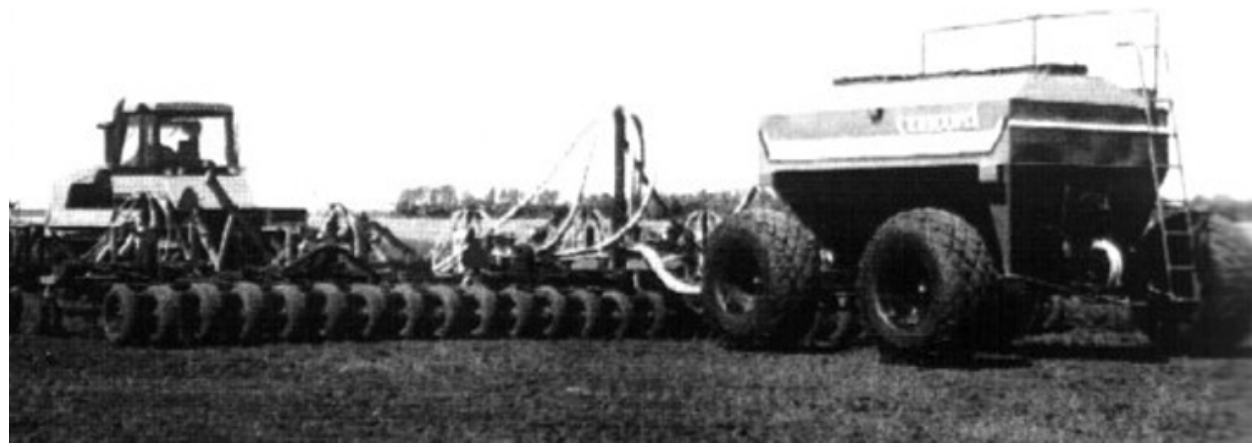

Fig. 4. Combined tillage and sowing complex Concord Case JH (USA).

Paw opener is used for seeding. Layout features: the cultivator frame has three sections, folding, the seed hopper is hitched on the back of the trolley, two CMS with two-stage distribution, rolling system of pneumatic wheels serving as the back support of the cultivator.

To increase productivity, the tillage and sowing complexes are made wide-spread (up to $18 \mathrm{~m}$ ), and trying to increase the hopper capacity capture up to $0.5 \mathrm{~m}^{3}$ per meter, to reduce the number of stops for refueling and to exclude refueling on field within the rut.

The placement of a heavy seed bin turned out to be a problem of tillage and sowing complexes layout. Usually use one hopper for seeds and fertilizer. But the capabilities of pneumatic systems make it possible to compose more complex complexes. So, Horsch company is building a tillage and sowing complex with two trailed bunkers: for seeds and fertilizers. It turns out whole road train, which is too problematically managed (fig. 5).

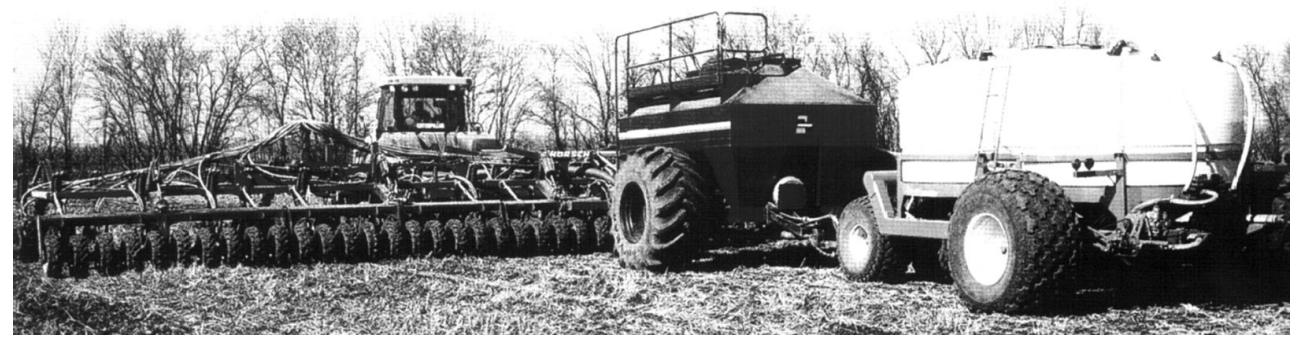

Fig. 5. Combined Sowing Unit Horch (Germany).

The weight and metal consumption of the unit increases to values that are detrimental to the field's fertility. Wide tires of powerful machines, although reducing the destruction of surface layers, are not able to cancel the compaction of deep layers to $1.5 \ldots 2.0 \mathrm{~m}$. Huge mass creates new problems.

Therefore, most sowing complexes are of width about $8 \mathrm{~m}$. The example is a sowing complex «Agromaster 8500» (fig. 6), having two bunkers on one cart and flat-cut paw openers. In one pass, pre-sowing cultivation of the soil, belt sowing of seeds with fertilizer application, harrowing, leveling and rolling of the soil is performed. It does not pretend for strip sowing. 


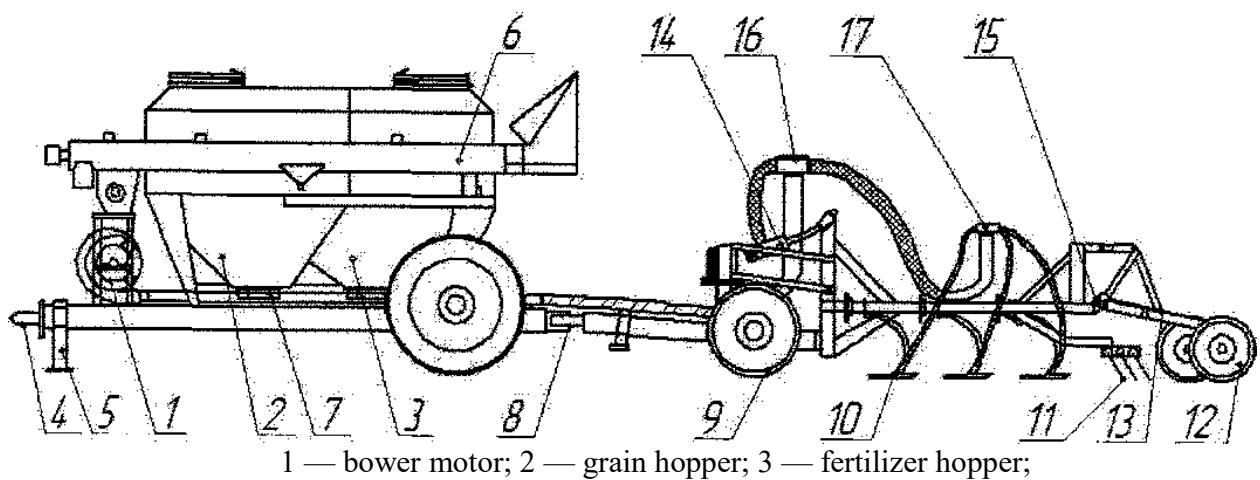

4,8 - thill; 5 - front support; 6 - filling auger; 7 - dosing device; 9 - supporting wheel; 10 — opener; 11 - harrow; 12 - supporting-rolling wheel; 13 - balancer suspension; 14,15 - lifting hydraulic cylinders; 16 - main distributor; 17 - secondary distributor

Fig. 6. Sowing complex «Agromaster $8500 »$.

Therefore, the task is to find a middle ground between constructive and technological solutions and zonal conditions which would ensure high crop yields at a minimum cost.

Promising direction is the use of combined units designed for surface tillage, both for sowing grain crops and for row crops, with the simultaneous application of mineral fertilizers and harrowing [6].

One of the important working bodies of combined strip sowing aggregates is the opener design, which is forming a furrow in soil of given depth, specific for every sowing crop, put seeds in it and cover it with soil [7].

Currently, designers, scientists and practitioners [8,9] are developing more advanced openers for planting grain seeds in soil, mainly of disk type (figure 1).

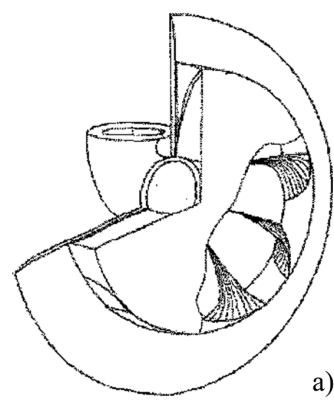

a)

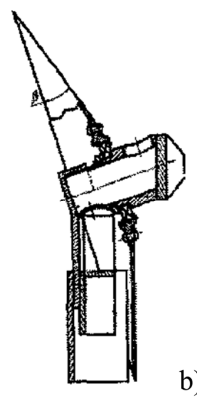

b)

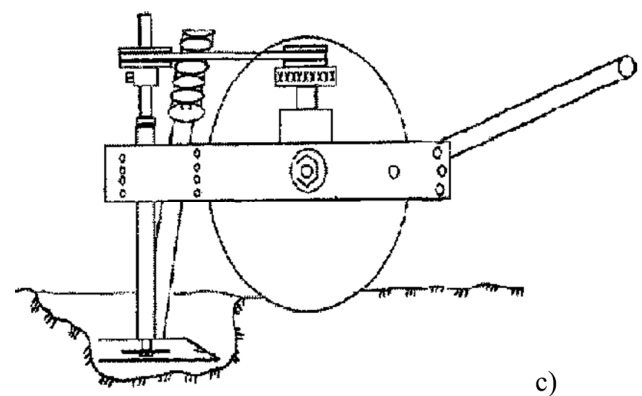

Fig. 7. Disc openers designs.

Opener with drum distributor (figure 7, a) allows to alternate the distribution zone of seeds across the sowing width. This effect is achieved by the fact that the drum - seed distributor is fixed on the disk opener, and the peripheral chambers are formed by impellers in the form of a curved surface.

Strip opener (figure 7, b) when sowing grain and leguminous crops provides a dense bed for seeds. Sowing seeds is carring out as a wide strip. As a result, stable, aligned seedlings are obtained, optimal conditions for nutrition of plants' root system are provided. However, the placement of the opener on the seeder frame complicates its design.[10]

Opener (figure 7, c) is intended for intra-soil sowing of grain crops, as well as the application of mineral fertilizers. Due to its design features, when sowing, an increase in the nutritional area of individual seeds is achieved due to a more uniform distribution over 
a wide strip. The disadvantage of such opener is the use of more energy-intensive tractors, part of the energy of which is spent on driving openers.

Analysis of working bodies design shows that it has a number of disadvantages. In particular, it does not have universality, which, in turn, leads to an increase in the number of technological operations for sowing crops. Also, for different climatic conditions, special working bodies are needed. As a result, there is a need to equip the sowing units with certain working bodies, or the use of other sowing units, which, ultimately, leads to a rise in the cost of manufactured products, as well as to increased time for sowing. [11]

\section{Justification for innovation}

Strip sowing of crops is considered a profitable alternative to the currently dominant row sowing.

Row sowing has gone a long way of improvement, and its working bodies have become typical - these are anchor, keeled and double-disc openers for grain seeders. But all of it have a number of drawbacks: small width of the sown strip and large traction resistance. For strip sowing a new opener that meets the requirements is needed:

a) opener must inherit achievements accumulated in agronomics;

b) design must be adapted to mass production;

c) simplicity of design.

The first requirement can be met by the use of disc openers; such openers have proven itselves in Russian agricultural fields in tillage and sowing equipment.

The second requirement is satisfied by the unification of opener parts with parts of mass-produced working bodies of agricultural machinery; as such unified design, it is proposed to use spherical disk of the diskator. Spherical disks are currently mass produced in a wide variety of types and sizes, this manufacturing technology is well established.[12[

The third requirement can be met if when moving away from the widely used opener hinge mount and limit it to hard mount to the frame. The function of copying the macrorelief in this case should be transferred to the entire seeder wheelset.

Creating a new typical form of old details carries signs of technical contradiction. The solution of such problems is carried out by heuristic methods. Using heuristic methods, it became possible to develop an innovative opener design which satisfies such conflicting requirements. Figure 8 shows the 3D model of the proposed new spherical disk opener.

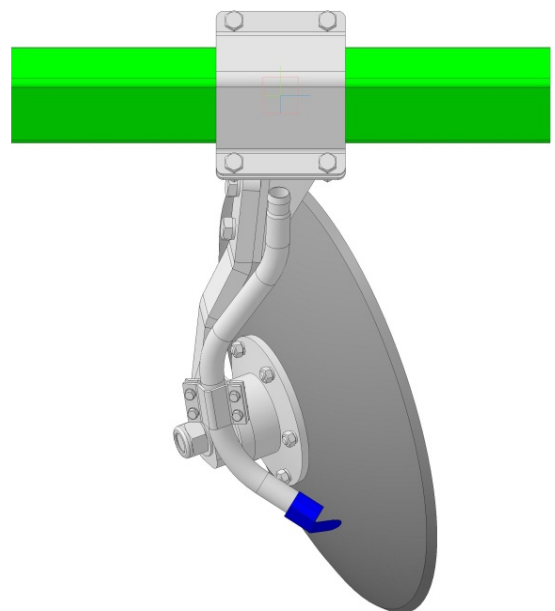

a)

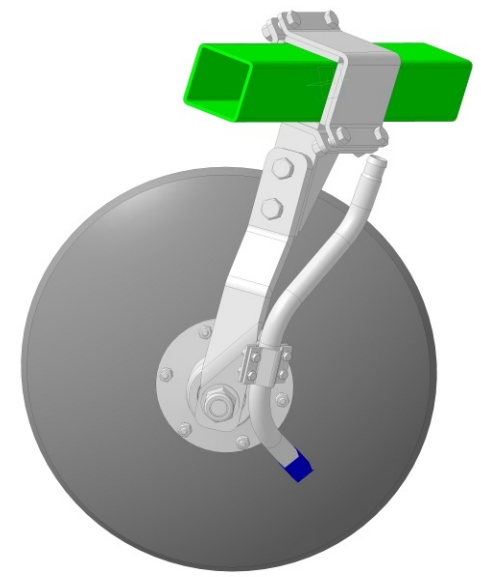

b)

1 - spherical disk; 2 - bearing; 3 - rack; 4 - rubberized bracket; 5 - frame; 6 - seed tube; 7 — distributor; 8 - seed tube mounting. 
Fig. 8. Spherical disc opener for strip sowing: $a$ — front view; $b$ — side view.

Spherical disc opener consists of an oblique spherical disk 1 from a diskator mounted on a bearing 2 on a rack 3 in class $\mathrm{Zh}$ (the angle of affrontality and tilt are not equal to zero). The rack 3 is attached to the beam of the frame 5 with an arm 4 in the form of a clamp through rubber brackets. On a rack 8 mounted a corrugated seed tube is fastened by clips. At the output of the seed tube the distributor 7 is fixed.

In general, the design is simple, consists of 8 parts and assemblies. It is unified as much as possible, out of 8 units unified with a diskator 4 units: the disk itself with a bearing assembly, rack, bracket. The corrugated seed tube 6 is unified too.

The technological process of sowing by this opener is as follows. Before starting work, the seeder frame is lowered and the depth of immersion of the disk edge into soil is set equal to the seed placement depth. When the seeder moves, its frame 5 moves horizontally and the spherical disk 3 receives rotation. It cuts a layer from soil with a sharp edge, loosens it, and shifts it to the side, forming a fairly wide groove. Seeds from the seed tube fall onto the type 7 distributor of the deflector, bounce off of it and disperse to the width of the furrow while it remains open. After sowing, the soil from the disk will partially crumble, and cover the sown seeds; this is how seeds are planted. Finally, the furrow is sealed behind by a running opener.

So on the field, bands of sown seeds are formed wider than in row crops. For a normal seeding stroke over the entire furrow width, it is necessary to fulfill the condition: seeds should fall on the ground at the last moment when the furrow remains open. This requires adjusting the position of the seed tube jet relative to the disc and its location is an important opener parameter.

\section{Conclusions}

Thus, on the basis of the analysis, we can conclude that the improvement of the working bodies of pre-sowing aggregates must be carried out taking into account the identified shortcomings.

\section{References}

1. E. Zubrilina, I. Markvo, V. Novikov, A. Beskopylny, L. Vysochkina, D. Rudoy, A. Butovchenko, IOP Conf. Series: Earth and Environmental Science 403, 012063 (2019) doi:10.1088/1755-1315/403/1/012063

2. S.I. Kambulov, I.V. Bozhko, A.V. Olshevskaya, MATEC Web of Conferences 224, 05022 (2018) https://doi.org/10.1051/matecconf/201822405022

3. A. Altybayev, A. Zhanbyrbayev, B. Meskhi, D. Rudoy, A. Olshevskaya, A. Prohorova, E3S Web of Conferences 135, 01078 https://doi.org/10.1051/e3sconf/201913501078

4. G. Parkhomenko, S. Kambulov, A. Olshevskaya, A. Babadzhanyan, N. Gucheva, I. Mekhantseva, IOP Conf. Series: Earth and Environmental Science 403, 012144 (2019) doi:10.1088/1755-1315/403/1/012144

5. Y. Lachuga, A. Soloviev, A. Matrosov, I. Panfilov, V. Pakhomov, D. Rudoy, IOP Conf. Series: Earth and Environmental Science 403, 012055 (2019) doi:10.1088/17551315/403/1/012055

6. L. Cbaorakam, M. Koike, T. Takigawa, Japan. Soc. Agr. 69(6), 65-74.1 (2007)

7. E.V. Demchuk, U.K. Sabiev, V.V. Mylo, A.S. Soyunov, V.S. Koval, Journal of Physics: Conference Series, 012009 (2018) 
8. A.S. Firsov, M.V. Nikiforov, A.V. Kudryavtsev, A.S. Vasiliev, A.V. Dichensky, V.V. Golubev, International Journal of Mechanical Engineering and Technology 9(11), 1917-1925 (2018)

9. N. Gupta, S. Goyal, H. Kur, International Journal on Emerging Technologies 10(2), 73-78 (2019)

10. J.R. Murray, J.N. Tullberg, B.B. Basnet, Planters and their components: types, attributes, functional requirements, classification and description (ACIAR (Australian Centre for International Agricultural Research), 2006)

11. L. Pesek, L. Pust, P. Snabl, V. Bula, M. Hajzman, M. Byrtus, Mechanisms and Machine Science 69, 169-259 (2019)

12. V. Ba, I.U. Auf, Akademie' agrarno usviti. 7, 62-77 (2019) 